\title{
Risk Factor for Malnutrition in Children Aged 6 to 59 Months Hospitalized in a Pediatric Ward in the South of the Sahara
}

\author{
A. A. Diakité, A. Diall, B. Maïga, A. Dembélé, F. L. Diakité, B. Coulibaly, L. N. Sidibé, \\ A. K. Doumbia, O. Coulibaly, P. Togo, G. Dembélé, A. Diall, M. Sylla
}

Department of Pediatrics, Gabriel Touré University Hospital, Bamako, Mali

Email: doc_abdela@yahoo.fr

How to cite this paper: Diakite, A.A., Diall, A., Maïga, B., Dembélé, A., Diakité, F.L., Coulibaly, B., Sidibé, L.N., Doumbia, A.K., Coulibaly, O., Togo, P., Dembélé, G., Diall, A. and Sylla, M. (2021) Risk Factor for Malnutrition in Children Aged 6 to 59 Months Hospitalized in a Pediatric Ward in the South of the Sahara. Open Journal of Pediatrics, 11, 329-338.

https://doi.org/10.4236/ojped.2021.113030

Received: April 26, 2021

Accepted: July 12, 2021

Published: July 15, 2021

Copyright $\odot 2021$ by author(s) and Scientific Research Publishing Inc. This work is licensed under the Creative Commons Attribution International License (CC BY 4.0).

http://creativecommons.org/licenses/by/4.0/ (c) (i) Open Access

\begin{abstract}
Malnutrition is a major public health problem in Mali, along with the country's political and security instability. We initiated this work with the objective of determining the frequency as well as the risk factors favoring the occurrence of malnutrition in children aged 6 - 59 months hospitalized in the pediatrics department of the Gabriel Touré University Hospital in Bamako, country reference service to identify potential interventions to plan. A cross-sectional study was carried out over a period of 4 months. A bivariate logistic regression analysis allowed us to identify risk factors with degree of significance if $\mathrm{p}<0.05$. During the study period, 2888 children were hospitalized, including 348 aged 6 to 59 months, or a frequency of $12.04 \%$. One in two children was malnourished, i.e. a frequency of $50 \%$. It more frequently affected infants aged between 6 and 23 months with a frequency of 33.7\%, with a hospital frequency of growth retardation which was $23 \%$ including $14.7 \%$ of severe form. The emaciation was $27 \%$ of which $18.7 \%$ were severe form. The underweight was $42.2 \%$ with $31 \%$ in severe form. We found the diet inequality in all malnourished and non-malnourished children. A bivariate analysis showed that children with an out-of-school mother have a 2.4-fold risk of being malnourished $(\mathrm{OR}=2.425 ; \mathrm{CI}=1.9-4.2 ; \mathrm{p}<0.03)$. Also children from households with no stable income (non-salaried father) have twice the risk of children from a household with stable income $(\mathrm{OR}=2.120$; IC $=1.1-4.1 ; \mathrm{p}<$ 0.002). Finally, inappropriate nutrients (early introduction of food and early weaning) have been strongly associated with the occurrence of malnutrition. The prevalence of malnutrition reflects the way children eat. Emphasis should be placed on nutritional education and financial stability in households.
\end{abstract}

\section{Keywords}

Malnutrition, Contributing Factors, Pediatrics 


\section{Introduction}

Malnutrition is a major public health problem in many countries of the world and is a priority in the Sustainable Development Goals (SDG2) [1]. It is both a medical and social disorder often rooted in poverty, defined by WHO as a pathological condition resulting from relative or absolute deficiency or excess of one or more essential nutrients, whether manifested clinically or detectable only by biochemical, anthropometric or physiological analyses. Malnutrition encompasses three groups of conditions: undernutrition, micronutrient malnutrition and overnutrition [2]. It affects vital functions, especially cognitive ones, especially in early childhood, and contributes significantly to the establishment of poverty through obstacles linked to a low learning and production capacity [3]. According to the United Nation annual report, 52 million children under the age of five are stunted, of which 17 million are severely stunted and 155 million are stunted [4]. Malnutrition plays a role in about $45 \%$ of deaths among children under five in low- and middle-income countries [5]. In West Africa, in 2014, $32 \%$ of children under five were chronically malnourished, $9 \%$ were acutely malnourished, and $20 \%$ were underweight [6]. Furthermore, it was estimated in 2008 that stunting, severe wasting and intrauterine stunting together were responsible for 2.2 million deaths in children under five years. [7]. The 2010 MICS survey reported a national prevalence of 9\% Global Acute Malnutrition (GAM) including 2\% Severe Acute Malnutrition (SAM), stunting (28\%) and wasting (19\%) [8]. Since 2012, Mali has been experiencing a politico-military crisis that has worsened the nutritional situation, as shown by the results of previous national studies [9]. In 2013, the EDSM-V reported a national prevalence of $13 \%$ GAM and 5.1\% SAM. According to the same survey chronic malnutrition remains a concern with a national prevalence of $38.3 \%$ and weight insufficiency of $26 \%$ [10]. According to the results of the SMART survey, the prevalence of GAM observed in all regions and the District of Bamako is 10.7\% including $2.6 \%$ of SAM, the rate of chronic malnutrition (23.1\%) and weight insufficiency (16.3\%) [9]. According to a study conducted in 2011 at the Gabriel Touré University Hospital, the rate of malnutrition of all types was $54.1 \%$, broken down as follows: $40.9 \%$ for stunting, $37.8 \%$ for underweight and $21.3 \%$ for wasting [11]. These child malnutrition rates have reached the critical threshold set by WHO. Thus, with the persistence of the country's political and security instability, this work was initiated with the objective of determining the frequency and risk factors favouring the occurrence of malnutrition in children aged 6 to 59 months hospitalized in the paediatric department of the Gabriel Touré University Hospital in Bamako, the country's reference service, with a view to identifying the potential for planning interventions.

\section{Methods}

The Intensive Nutritional Recovery and Education Unit (INREU) of the Paediatric Department of the Gabriel Touré University Hospital in Bamako served as 
the study setting. It is a reference unit in the country in the nutritional care of malnourished children hospitalized in all the services of the said department (Neonatology service to which it is attached, general paediatrics service, paediatric emergency service and the paediatrique oncology unit). Since its inception in 2008 , it has provided annual nutritional recovery to approximately $1000 \mathrm{mal}-$ nourished for associated complications. This is a prospective cross-sectional study over a period of 4 months from 01 June 2019 to 30 September 2019. All children aged 6 - 59 months hospitalized in the paediatric department during the period and whose parents or carer consented. A medical file was opened for each patient from which an individual survey was made. A questionnaire was submitted to the parents or carers of the children in order to collect information about the children. The variables studied were: socio-demographic characteristics of the parents (Residence, level of education, household income, soci-economic conditions), clinical characteristics of the patient (age, sex, weight, height), diagnostic criteria (weight/height ratio measures acute malnutrition or emaciation, weight/age measures underweight and height/age measures chronic malnutrition or stunting).

The sampling was exhausted.

The parameters were defined as follows [10]:

1) Emaciation or acute malnutrition: a child is emaciated if his or her weight-for-height $\mathrm{Z}$-score is less than 2 standard deviations (-2SD) from the median of the reference population are considered lean (moderately emaciated) or acutely undernourished. When the $\mathrm{Z}$-score is below minus 3 standard deviations (-3SD) is considered severely emaciated.

2) Stunting or chronic malnutrition: children whose Z-score for height for age is less than 2 standard deviations $(-2 \mathrm{SD})$ from the median of the reference population are considered too short for their age (stunting) or chronically undernourished. Children below minus 3 standard deviations (-3SD) are considered severely stunted.

3) Underweight or undernourished: children whose weight-for-age Z-score is less than 2 standard deviations (-2SD) from the median of the reference population are considered moderately underweight. Children with a weight-for-age Z-score below minus 3 standard deviations $(-3 \mathrm{SD})$ from the median are considered severely underweight.

Data entry and analysis were carried out using SPSS software (version 20.0). A bivariate logistic regression was fitted to identify the factors influencing the occurrence of malnutrition with determination of the odds ratio, the $95 \%$ confidence interval and significant $\mathrm{p}$ if $\mathrm{p}<0.05$. Informed consent from parents or carers was required before participation in the study.

\section{Results}

During the study, 12\% of those hospitalised (348 out of 2888) were between 6 and 59 months of age. One child out of two was malnourished, a frequency of 
$50 \%$.

The majority of children had become malnourished before their second birthday (6 - 23 months) in 33\% of cases. The hospital incidence of stunting was found to be $23 \%$, of which $14.7 \%$ were severe. Wasting was $27 \%$ with $18.7 \%$ severe. Weight insufficiency was $42.2 \%$ with $31 \%$ severe. The majority of cases were male (29\%) with a sex ratio of 1.3 (Figure 1 ). Regarding the socio-economic conditions of our malnourished patients, we noted that a significant number of fathers did not have a fixed salary, $18 \%$ of whom were workers. Housewives were in the majority in $45.1 \%$ and had not received any education in $30.2 \%$ of cases (Figure 2). For the feeding habits of children aged 6 to 59 months, poor feeding practices were observed in both malnourished and non-malnourished groups. But in the malnourished group, most of these children were predominantly breastfed (39.4\%). The majority (36.8) of children had started to receive other foods corresponding to diversification between 6 - 12 months and porridge was the food in question of breastfeeding was early (0 - 18 months) in $12.6 \%$ and unprepared in $24.7 \%$ of cases (Figure 3 ). The pathologies most associated with malnutrition were gastroenteritis in $31.6 \%$ followed by acute respiratory infections (ARI) in 17.8 and malaria in $15.5 \%$ of cases (Figure 4 ).

A bivariate analysis showed that children with an out-of-school mother were 2.4 times more likely to be malnourished ( $\mathrm{OR}=2.425 ; \mathrm{CI}=1.9-4.2 ; \mathrm{p}<0.03$ ).

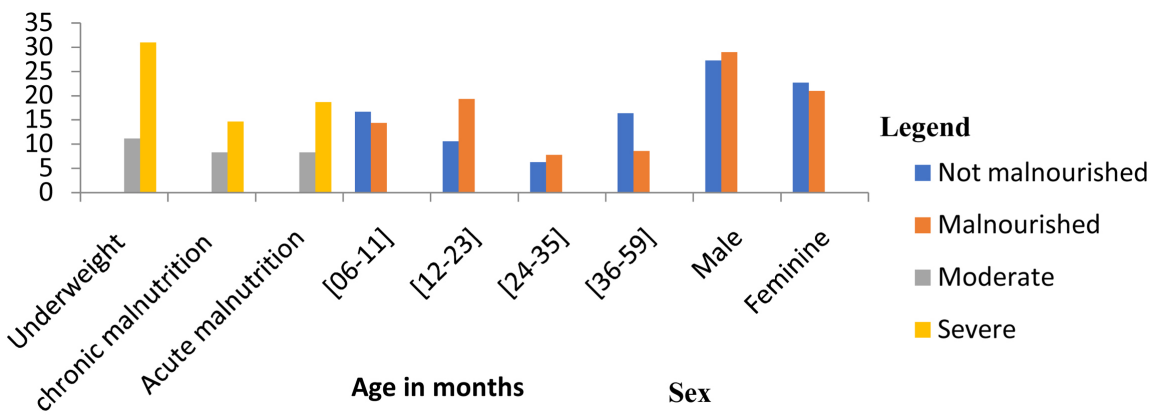

Type of malnutrition

Figure 1. Distribution of children by clinical characteristics of children.

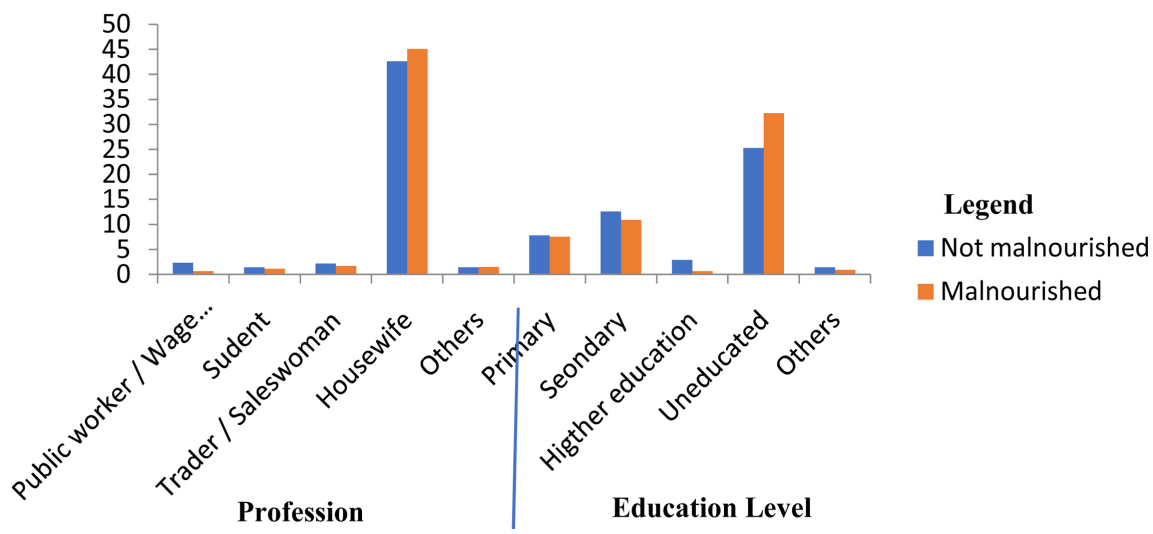

Figure 2. Distribution of children by mothers' characteristics. 


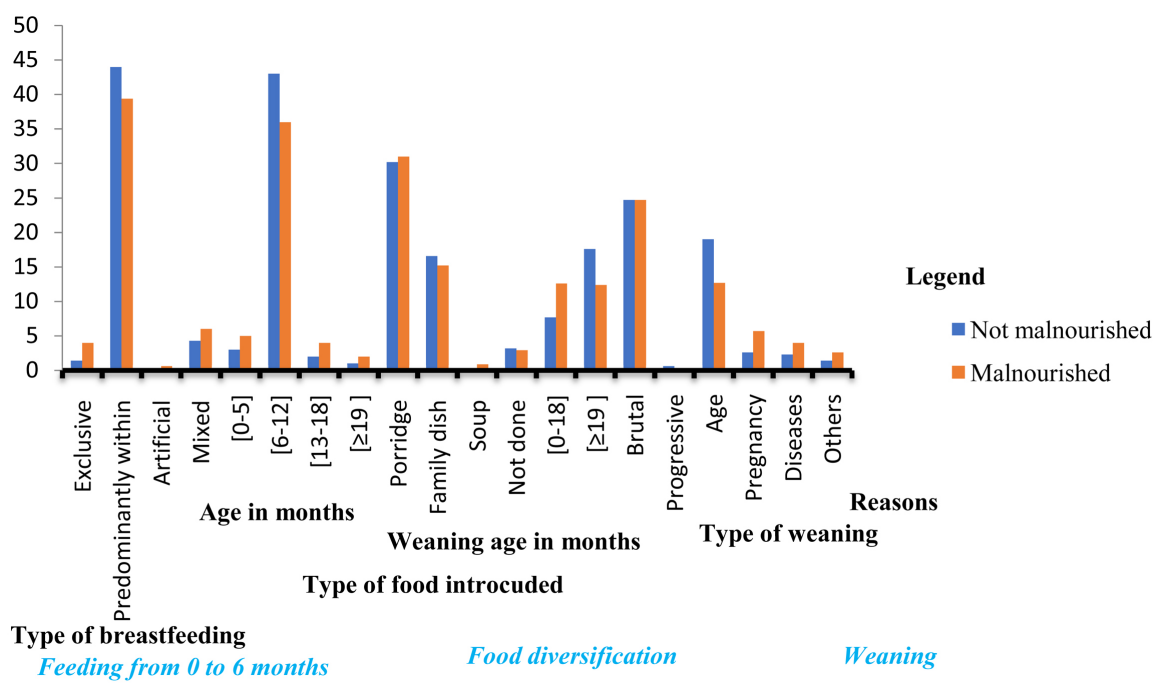

Figure 3. Distribution of children by child nutrition.

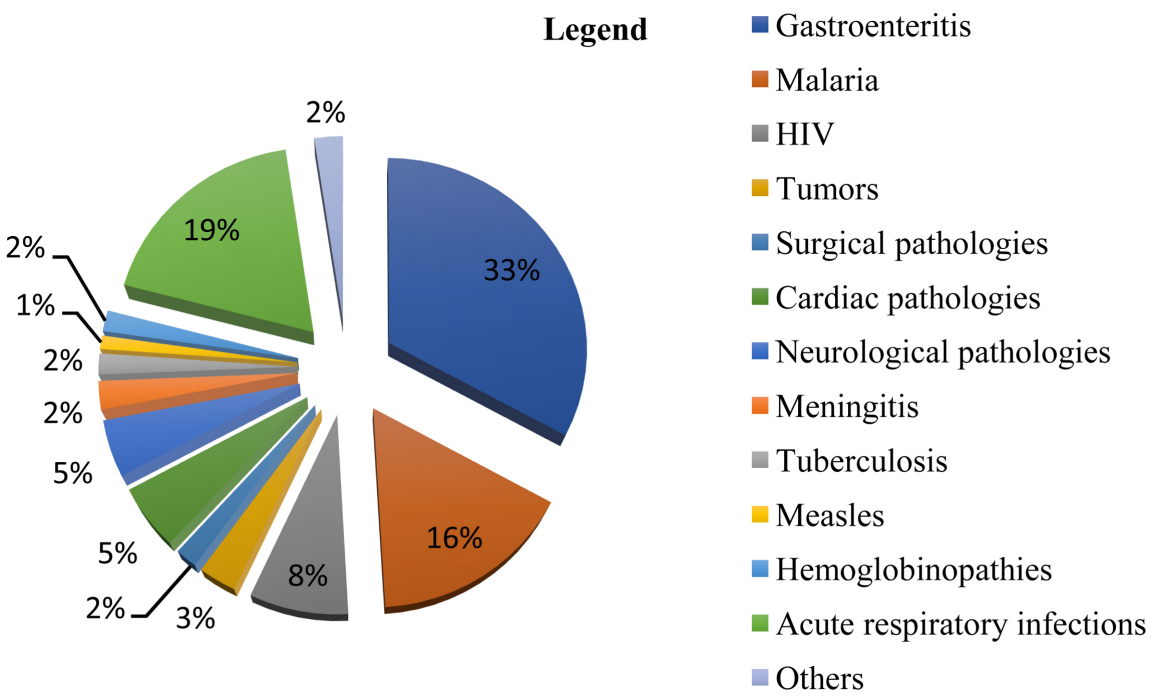

Figure 4. Distribution of children according to pathologies associated with malnutrition $\mathrm{n}=174$.

Also children from households with no stable income ( $\mathrm{OR}=2.120 ; \mathrm{CI}=1.1$ 4.1; $\mathrm{p}<0.01)$. finally, poor child feeding practices such as early introduction of food before 6 months of age and early weaning increased the risk of malnutrition by 1.6 and 2.3 times, although the association was only significant for early weaning $(\mathrm{OR}=2.31 ; \mathrm{CI}=1.2-4.2 ; \mathrm{p}<0.01)($ Table 1$)$.

\section{Discussion}

\section{Limitations and Difficulties Encountered}

We conducted a cross-sectional study. This type of study makes it possible to take stock of a given question in a given environment, during a given period, taking into account the realities of the field (the hospital). We used data from a survey we conducted in the pediatric department. As malnutrition is a sensitive 
Table 1. Risk factors for the occurrence of malnutrition.

\begin{tabular}{lcc}
\hline \multicolumn{1}{c}{ Risk factors } & OR (IC) & Value P \\
\hline Introduction of additional feed (months) & $1.638(0.768-3.493)$ & \\
$<6$ & 1 & 0.197 \\
$\geq 6$ & $2.312(1.246-4.289)$ & \\
Weaning age (months) & 1 & 0.007 \\
$0-18$ & $1.242(0.736-2.096)$ & \\
$\geq 19$ & 1 & 0.417 \\
Mother'sage (year) & & \\
15 - 30 & $2.425(1.930-4.185)$ & \\
$>30$ & 1 & 0.037 \\
Mother'slevel of education & & \\
Not in school & $2.120(1.093-4.113)$ & \\
Educated & 1 & 0.023 \\
Father's professional activities & & \\
Not employed & & \\
Public worker/Wage earner & & \\
\hline
\end{tabular}

OR: Odds Ratio, IC: Confidence Interval.

subject, we have difficulty in getting answers to some of the questions.

During the course of our study (from 1 January to 30 September 2019), we identified 348 children who met our inclusion criteria. Acute malnutrition was detected in $27 \%$ of the children, chronic malnutrition in $23 \%$ and weight insufficiency in $42.2 \%$. Our results are up from national data which in the 2018 GDHS-VI [12] estimated 9\% acute malnutrition 27\% chronic malnutrition and 19\% weight insufficiency. According to the SMART 2018 survey [13], acute malnutrition represents $10 \%$, chronic malnutrition $24.1 \%$ and weight insufficiency $18.6 \%$. This high rate is explained by the fact that our study only involved children who were hospitalised. The majority of malnourished children were male (29\%) with a sex ratio of 1.3 . This result is identical to those reported by Kngaye S et al. (ratio of 1.3) [14] and the SMART 2017 survey (ratio of 1.3) [9]. Unlike our study, Savadogo AS [15] and Musimwa AM and al [16] found a sex ratio of 0.45 and 0.7 respectively. This male predominance in our study cannot be explained by our survey method; we did not find any study that could explain it. The mean age was $1761 \pm 11,297$ months standard deviation (SD) with extremes of 6 and 59 months. The 12 - 23 month age group was the most affected, with $19.3 \%$ of malnourished cases. Maiga B et al. [17] reported a frequency of $58.5 \%$ in this same age group. According to Kangaye $S$ et al. [14], the age group most affected by malnutrition is 6 to 23 months (66.2\%). On the other hand, Musimwa AM et al. [16] and Diarra B [18] reported in their studies that the 24 35 month age group was the most represented. Our result can be explained by the difficulties related to diversification at this age, which in most cases is not carried out under ideal conditions, and also early weaning in favour of close 
pregnancies and illness of children. Most mothers of malnourished children were housewives $(45.1 \%)$ and multiparous $(23.9 \%)$. They were financially dependent on their husbands, most of whom had low incomes. These couples with low socio-economic status are vulnerable and any children born to them are at risk of malnutrition. Ouédrago SO et al. [19] in their study reported that 90.7\% of parents of malnourished children had a low socio-economic level. Kouakou JG et al. in their study on the prevalence of malnutrition and determining factors, showed that when the father's professional activity did not guarantee adequate income, this could multiply the risk of malnutrition by 3 [20]. In contrast, in our study, the mothers' level of education $(\mathrm{OR}=2.425 ; \mathrm{p}<0.03)$ and the fathers' professional activity $(\mathrm{OR}=2.120 ; \mathrm{p}<0.02)$ are determining factors for malnutrition. A large majority of malnourished children (39.4\%) were predominantly breastfed up to 6 months, compared to $4 \%$ of children who were exclusively breastfed. This result is similar to Kouakou JG et al. [20], who reported that one child in ten was exclusively breastfed. Our result differs from that of the EDSM-V, which reported 33\% exclusive breastfeeding [10]. The low rate of exclusive breastfeeding our study could perhaps be explained by the analphabétisation of parents which results in insufficient information about the benefits of exclusive breastfeeding. Diversification started between $6-12$ months of age in $36.8 \%$ of the children with an average of 6.94 months \pm 2.5 ET. The same age range was observed by Maiga B et al. [17] in 66.4\% with an average of 8 months weaning of malnourished was done mostly (14.9) between 0 - 18 months. This could be explained by the high rate of uneducated housewives. We found that gastroenteritis was frequently associated with malnutrition (31.6\%). This result is close to that of Musimwa AM et al. [16] who, in a study of clinical data encountered in malnourished children, described diarrhoea as the first association with malnutrition with a frequency of $38.5 \%$. Ouedrago SO et al. [19] and Thiam L et al. [21] reported high rates of diarrhoea associated with malnutrition with $60.9 \%$ and $29.8 \%$ of cases respectively. Indeed, malnutrition leads to deterioration of the intestinal mucosa, thus limiting absorption, hence the high frequency of diarrhoea in all authors.

We recorded $17.8 \%$ of cases of acute respiratory infections associated with malnutrition. Ngirabega JD et al. [22] reported 45.3\%, Musimwa AM et al. [16] (42.5\%) and Thiam L et al. [21] (29,9\%). These results corroborate with the clinical condition of malnourished children who are prone to many infections due to a failure of their immune systems. Our study took place during the winter period, which is favourable of the proliferation of mosquitoes. Thus, malaria was associated with malnutrition in $15.5 \%$ of cases. Our result is close to those of Thiam L et al. [21] and Ngirabega JD et al. [22] who found respectively 10.5\% and $11.9 \%$. To determine the risk factors for malnutrition, we assessed the following variables: diversification, age at weaning, mother's age, mother's education and father's occupation. We were able to establish an association between age of diversification and malnutrition with $\mathrm{OR}=1.638(0.768-3.493)$. This association was not significant $(\mathrm{p}<0.19)$. Aouehougon [23] in his study showed 
that there was no significant association between diversification and malnutrition ( $\mathrm{p}<0.88$ ). Unlike us, Nyime [24] reports a statistically significant ( $\mathrm{p}<$ 0.02).

Our result could be explained by the fact that we were not able to receive precise informationon the age of diversification. In contrast, we found a statistically significant association between weaning and malnutrition $(\mathrm{OR}=2.312 ; \mathrm{p}<$ 0.01 ). This may be explained by the difficulties young mothers have in weaning, which is generally poorly conducted because infants are often weaned early. The association is statistically significant between mothers' level of education and malnutrition $(\mathrm{OR}=2.425 ; \mathrm{p}<0.03)$. Aouehougon [23] reached the same result with $(\mathrm{OR}=1.5 ; \mathrm{p}<0.03)$. Our result could perhaps be explained by the high number of uneducated mothers. Through instruction, mothers acquire better knowledge about malnutrition, different types of food and hygiene. The association of mothers' age with malnutrition was not significant $(\mathrm{OR}=1.242 ; \mathrm{p}<$ 0.417) in our study. As for Kouakou J G et al. [20] ( $\mathrm{p}<0.42)$.

However, the association between the father's professional activity and malnutrition was statistically significant $(\mathrm{OR}=2.120 ; \mathrm{p}<0.02)$. Kouakou J G et al. [20] also found this association significant, with $(\mathrm{OR}=2.77$; $\mathrm{p}<0.01)$. In contrast to these results, Nyime [24] reported that there was no association $(\mathrm{OR}=$ 4.422; $\mathrm{p}<0.12$ ) between socio-economic level and malnutrition. Our result could be explained by the fact that most of the fathers (labourer, farmer) had a low income, unable to meet the nutritional requirements of the children.

\section{Conclusion}

Malnutrition remains a preoccupying situation in Mali. This high incidence is a reflection of children's eating habits and the country's financial situation. The focus should be on nutritional education and improving living conditions in our families.

\section{Conflicts of Interest}

None.

\section{References}

[1] UNICEF-WHO-World Bank (2015) Levels and Trends in Child Malnutrition Group Joint Child Malnutrition Estimates Key Findings of the 2015 Edition United Nations Children's Fund, New York: http://www.unicef.org/

[2] Ag Iknane, A., Bah, R. and Diarra, M. (2011) Touré Aminétou. Basic Elements of Human Nutrition. Harmattan Sahel, 1, 78.

[3] United Nations Children's Fund (1998) The State of the World's Children 1998. https://www.unicef.org/french/sowc98/pdf

[4] World Health Organization (2017) World Hunger on the Rise again, Driven by Conflict and Climate Change 2017.

[5] World Health Organization (2020) Children: Reducing Mortality. http://www.who.int/fr/news-room/fact-sheets/detail/children-reducing-mortality 
[6] Office for the Coordination of Humanitarian Affairs (2015) Sahel, a Call for Humanitarian Aid. Responding to the Need of People Affected by Crisis in the Sahel 2015 https://reliefweb.int/report/mali/sahel-call-humanitarian-aid-responding-needs-peo ple-affected-crises-sahel

[7] Horton, R. (2008) Maternal and Child Undernutrition: An Urgent Opportunity. The Lancet, 371, 179. https://doi.org/10.1016/S0140-6736(07)61869-8

[8] Multiple Indicator Cluster Survey 2009-2010 Bamako-Mali 2011, 49. http://www.instat-mali.org/contenu/eq/ramics10 eq.pdf

[9] National Retrospective Mortality and Anthropometric Nutritional Survey Following the SMART. Online, Mali, 18-27.

[10] Cellule de Planification et de Statistique, Institut National de la Statistique and Centre d'Études et d'Information Statistiques (2014) Demographic and Health Survey in Mali 2012-2013. ICF International, Rockville, 180-577.

https://dhsprogram.com/pubs/pdf/fr286/fr286.pdf

[11] Diall, H.G., Diakité, A.A., Traore, F., Toure, A., Maiga, B., Traore, I., Sacko, K., et al. (2019) P-510: Prevalence of Malnutrition among Children Hospitalised in the Paediatric Ward of the Gabriel Touré University Hospital from May 2011 to April 2012. Archives of Paediatrics, 22, 363. https://doi.org/10.1016/S0929-693X(15)30686-2

[12] Demographic and Health Survey in Mali 2018, 209-604. Online. http://www.instat-mali.org/contenu/eq/ramics19 eq.pdf

[13] National Retrospective Mortality and Anthropometric Nutritional Survey Following the SMART. Online, Mali, 51-60.

[14] Kangaye, S., Moumouni, K., Ibrahim, A., Soumana, A., et al. (2019) Correlation between Reasons for Hospitalisation and Nutritional Status in Children Aged 6 - 59 Months Hospitalized in Emergency in Two Referral Hospitals in Niamey, Niger in 2016. European Scientific Journal, 15.

[15] Savadogo, A.S. (2007) Malnutrition in Children Aged 0 - 5 Years at the Nianankoro Hospital in Segou. Medical Thesis, Online, Bamako, 61-69. Savadogo AS.

[16] Musimwa, A.M., Kanteng, G.W., Kitoko, H.T. and Luboya, O.N. (2016) Clinical Signs of Malnutrition in Children Living around a Mining Area: A Case Study in the City of Lubumbashi and Its Surrounding. Pan African Medical Journal, 24, Article No. 67.

[17] Maiga, B., Sacko, K., Diall, H., Dembele, A., Traoré, F., Doumbia, A.K., et al. (2019) Epidemiological and Clinical Aspects of Severe Acute Malnutrition in Children under Five Years of Age at the Gabriel Touré University Hospital. Health Sciences and Disease, 20, 74-77.

[18] Diarra, B. (2010) Evaluation of the Nutritional Status of Children Aged 0 - 59 Months in Four Circles of the Tombouctou Region (in Rural Areas). Medical Thesis, Online, Bamako, 102-113

[19] Ouedrago, S.O., Koueta, F., Dembele, E., Konate, C.B., et al. (2013) Risk Factors for Mortality during Severe Acute Malnutrition in the Paediatric Ward of the Regional Hospital Centre (RHC) Kaya. Clinics in Mother and Child Health, 10.

[20] Kouakou, J.G.S., Aka, B.S., Hounsa, A.E., Attia, R., Wilson, R., Ake, O., et al. (2019) Malnutrition: Prevalence and Risk Factors among the Children Younger than Five Years in a Semi-Urban Area of Abidjan. Médecine et Santé Tropicales, 26, 312-317. https://doi.org/10.1684/mst.2016.0591

[21] Thiam, L., Niang, B., Diouf, F.N., Coly, I.J., Dramé, A., Issa, R.T., et al. (2019) Eval- 
uation of Undernutrition in Children Aged between 2 and 60 Months Hospitalised in the Paediatric Wards of Ziguinchor Hospitals.(Sénégal). European Scientific Journal, 14, 452-459. https://doi.org/10.19044/esj.2018.v14n3p452

[22] Ngirabega, J.-d.-D., Munyanshongore, C., Donnen, P. and Dramaix, M. (2019) Influence of Malnutrition on Child Mortality in a Rural Hospital in Rwanda. Journal of Epidemiology and Public Health, 59, 313-318.

https://doi.org/10.1016/j.respe.2011.05.002

[23] Aouehougon, O. (2007) Protein-Energy Malnutrition and Its Risk Factors in Children under Five in the Touga Health District. Burkina Faso, Mémoire Online.

[24] Tshiabela Nyime, J.P. (2020) Protein-Energy Malnutrition and Its Risk Factors in Children under Five in the Kisenso Area. Kinshasa (RDC), Mémoire Online. 